\title{
Ocean Wave Energy Hydrogen System for Electrification
}

\author{
Abdul Majeed Muzathik \\ Department of Mechanical Engineering, Faculty of Engineering, South Eastern University of Sri Lanka, Oluvil, Sri Lanka
}

Email address:

muzathik64@yahoo.com

\section{To cite this article:}

Abdul Majeed Muzathik. Ocean Wave Energy Hydrogen System for Electrification. International Journal of Sustainable and Green Energy. Vol. 6, No. 2, 2017, pp. 19-27. doi: 10.11648/j.ijrse.20170602.12

Received: June 1, 2017; Accepted: June 15, 2017; Published: July 20, 2017

\begin{abstract}
Human population growth and development activities, growing at a rapid pace today, have increased the energy demands. Global concerns over above facts linked to fossil fuel consumption have increased the pressure to generate power from renewable sources. Owing to present day's energy crisis, growing environmental concern and escalating cost of fossil fuels, we ought to take every effort to supplement our energy base with renewable sources. Without any doubt, renewable energy, especially solar, wind and wave energy will play an important role in 21 st century. Main disadvantage of wave power is its largely random variability in several time-scales, from wave to wave, with sea state, and from season to season. Present situation shows a wide variety of wave energy systems, at several stages of development, competing against each other, without it being clear which types will be final winners. In last few years, interest in wave energy utilization has been growing rapidly in all over the world. High costs of constructing, deploying, maintaining and testing large prototypes under harsh environmental conditions, has hindered the development of wave energy systems. In this paper, some wave parameters have been discussed that are related to transport, generation and variability of wave energy in the sea. Wave Energy Converters (WECs) are classified into different groups. In order to develop a commercial WEC is not a straightforward task. Many inventions still have to be made, and many challenging problems need to be solved.
\end{abstract}

Keywords: Population Growth, Energy Demand, Fossil Fuel, Environmental Concern, Wave Energy Systems

\section{Introduction}

Energy is a key element with reference to the interactions between nature and society and is also considered as a key input for economic development. Environmental issues span a continuously growing range of pollutants, hazards and ecosystem degradation factors that affect areas ranging from local through regional to global scales. Many environmental issues are caused by or relate to the production, transformation and use of energy [1-2]. Global concerns over above facts linked to fossil fuel consumption have increased the pressure to generate power from renewable sources [1-2].

The human population growth and development activities, growing at a rapid pace today, have increased the energy demands. Owing to the present day's energy crisis, growing environmental concern and escalating cost of fossil fuels, we ought to take every effort to supplement our energy base with renewable sources. As environmental and sustainability issues arise with our current energy system (fossil fuel based), pressure is being applied on policy makers, governments, and the energy sector, to provide for our typical energy requirements, in sustainable manner. In response, a variety of 'road maps' for the future of our energy systems have been tabled which boldly state that energy from renewable sources (wind, solar, wave, biomass, etc.) will become a major contributor to the energy mix in the next few decades.

Countries like Denmark which have lead the way in incorporating renewable energy (especially wind and wave) into their energy systems have published energy plans which target 50 percent renewable energy by 2030 and 100 percent by 2050 [3]. The European Commission aims to supply $20 \%$ of final energy consumption from renewable energy sources by 2020 [4]. Legislation, recently passed in many states of U.S., requires that state energy companies provide between 25 to $30 \%$ of their power from renewable energies by 2020 [5]. In China, renewable energy aims to contribute $10 \%$ of the national energy supply by year 2020 [6]. Without any doubt, renewable energy, especially solar, wind and wave energy will play an important role in the 21 st century.

In the last two decades, solar, wind and wave energies are seen as alternatives to traditional energy sources. These 
alternative energy sources are non-polluting, free in their availability and renewable. But high capital costs have slowed down the tapping of their growth potential. In recent years, advanced materials, the capacity to be interconnected with the grid and better manufacturing processes have decreased their capital costs, making them more attractive. Another way to decrease the cost of these systems is by making use of hybrid designs which are based on solar-wind-wave energy. The question is which configuration will be the most cost effective, while meeting the demands. The other goal of this study was to evaluate the performance and reliability of a standalone renewable energy system using hydrogen. Performance was based on how well the system met its energy demand and the cost.

Although substantial advances in renewable energy technologies have been made, significant challenges remain in developing integrated renewable energy systems primarily due to the mismatch between load demand, source capabilities and cost $[2,7]$. While cost is an important factor, it must be evaluated relative to the true impact of the existing energy technologies. Power from these resources may not be available when required. The output from renewable energy sources like solar, wind, wave, tidal and micro-hydro fluctuate on an hourly, daily, and seasonal basis. As a result, these devices are not well suited for directly powering loads that require a uniform and uninterrupted supply of input energy.

In order for the renewable energy systems to be competitive, they have to be adapted to the local renewable energy climate and demand. If one has more detailed knowledge of the renewable energy climate of a particular site, the easier it is for designers of renewable energy systems to optimize the technology and make it competitive. Renewable energy production is closely related with the renewable energy climate in the concerned region. However, the development of new renewable energy projects continues to be hampered by the lack of reliable and accurate renewable energy data in many parts of the world.

The limitations of solar, wind and wave power are sitespecific, intermittent and thus, not reliable for instantaneous supply. In many situations, improving the availability of most renewable sources would require an energy storage media between the resource and the load to bank excess energy, when available, to buffer the output during periods where load demand exceeds the renewable input [2, 8-9]. Furthermore, different types of storage media are required to service short-term transients and long duration time scales. Short-term means for storing electricity once produced are limited to batteries, magnetic fields and super-capacitors. Of these, batteries are the only commonly used commercial devices but have low energy densities. Energy storage and power capacities are inherently coupled. Batteries are also considered short-term storage devices since they typically lose 1 to $5 \%$ of their energy content per day through selfdischarge [10].

In remote off-grid locations, operation from renewable resources normally requires large lead-acid battery buffers to address the issue of supply fluctuations. The physical size, limited life span, and initial capital cost of the battery bank coupled with transportation, maintenance, and battery disposal issues imposes significant limitations on the load capacity [10]. Significant improvements may be possible by storing the energy in the form of hydrogen instead of using batteries. Renewable energy, hydrogen systems for remote area and offshore power supply are potentially at an early stage of zero-emission hydrogen energy technology because of the high costs of conventional energy sources in such applications [11]. Hydrogen is also renewable when it is produced from renewable energy sources. When it is converted into useful energy in the form of electricity via a fuel cell, the by-product is harmless water. As a result, hydrogen energy is indeed an ideal energy carrier in the future. In the United States, Australia, Germany, Japan, China and many other countries, researchers and government officials have realized the vision of hydrogen economy.

Many of the islands are not provided with grid based electricity [12]. In addition to energy demand in mainland, the energy demand in isolated small islands is also steadily increasing and hence, it is very important to find some new schemes to meet the continually increasing demand of power in isolated small islands. One of the solutions for these issues is to integrate different forms of ocean renewable energy. Renewable energy research has mostly focused on the development of solar, wind, biomass and geothermal sources. While these sources are all very promising, the best and most robust energy policy will take advantage of a full suite of renewable energy sources. Wave energy has long been considered as one of the most promising renewable technologies. Not only is the energy resource vast, but also is more dependable than most renewable energy resources, wave power at a given site is available up to $90 \%$ of the time, while solar and wind availability tend to be available only $20-30 \%$ of the time [6].

The wind, solar and wave power into a hybrid hydrogen system is a new research area and no literature could be found other than few referring to renewable energy resource assessment [13-16]. Therefore, here the studies of integration are expanded to include solar (photovoltaic), wind and wave energy in a hybrid hydrogen power system to provide sustainable zero-emission energy at study area.

\section{Type of Wave Energy Converter (WEC)}

Over the last few years there has been a renewed and increasing interest in transforming ocean wave energy into electricity. So far, many different concepts of devices have been proposed. Of these, some have achieved the prototype state, already having faced real sea conditions, and in fact it might be more than one converter type that reaches the stage of large-scale implementation. It is likely that several different concepts will become viable, partly depending on site characteristics. Generally, the existing devices are 
classified according to the distance between the location of the installation and the shore. Shoreline devices do not require long underwater electrical cables or deep-water moorings.

Impressed by the power of ocean waves, inventors have, for more than two centuries, proposed many different devices for utilizing wave power. Although these techniques are generally not as far developed yet, it is likely that wave power will become at least as important as wind and hydropower [17]. The many different proposals and principles for wave energy conversion may be classified in several ways.

Unlike large wind turbines, there is a wide variety of wave energy technologies, resulting from the different ways in which energy can be absorbed from the waves, and also depending on the water depth and on the location (shoreline, near-shore, offshore). These are useful for considering the differences and similarities between various WECs. They may be classified according to location (off-shore, near-shore or onshore; floating, submerged or bottom-standing), type of energy conversion machinery (mechanical, hydraulic, pneumatic or directly electrical) and type of energy for end use (electricity, water pumping, desalination of seawater, refrigeration, water heating, propulsion).

WECs may also be classified according to their horizontal extension and orientation. If the extension is very small compared to a typical wavelength, the WEC is called a point absorber. On the contrary, if the extension is comparable to or larger than a typical wavelength, the WEC is called a line absorber, but the terms attenuator and terminator are more frequently used. A line absorber is called an attenuator or a terminator if it is aligned parallel or normal to the prevailing direction of wave propagation, respectively. Recent reviews identified about one hundred projects at various stages of development. The number does not seem to be decreasing: new concepts and technologies replace or outnumber those that are being abandoned [18].

\subsection{The Oscillating Water Column (Fixed-Structure and Floating-Structure)}

The first oscillating water column (OWC) converters deployed in the sea were floating. The air flow displaced by the motion of the OWC drives an air turbine, which has been considered for larger scale energy production. The floating OWC devices are largely free to oscillate or tension moored to the sea bed shown in Figure 1 [19]. In general the fixed structure devices stand on the sea bottom or are fixed to a rock. Shoreline devices have the advantage of easier installation and maintenance. The less energetic wave climate at the shoreline can be partly compensated by natural wave energy concentration due to refraction and diffraction. The typical first generation device is the OWC. The OWC device comprises a partly submerged concrete or steel structure, open below the water surface, inside which air is trapped above the water free surface. The oscillating motion of the internal free surface produced by the incident waves makes the air to flow through a turbine that drives an electrical generator. The design and construction of the structure are the most critical issues in OWC technology, and the most influential on the economics of energy produced from the waves, the civil construction dominates the cost of the OWC plant.

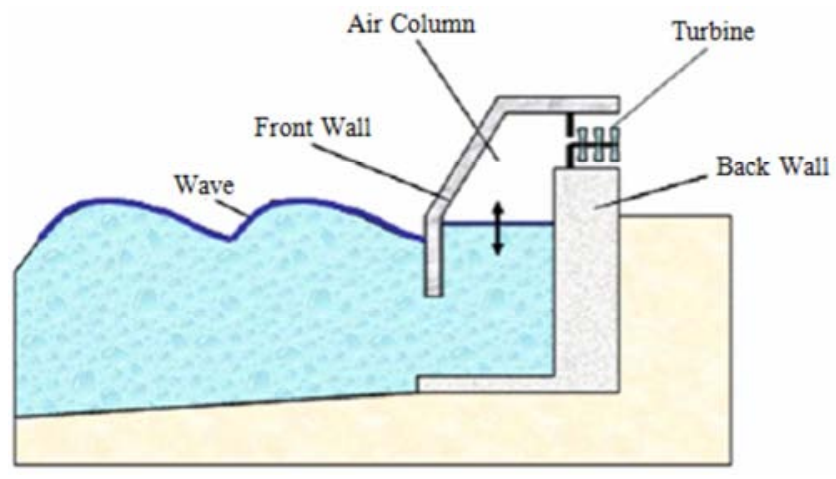

Figure 1. The oscillating water column [19].

\subsection{Oscillating Body Systems}

Offshore WEC devices are basically oscillating bodies, either floating or fully submerged. They exploit the more powerful wave regimes available in deep water (more than $40 \mathrm{~m}$ ). Offshore WECs are in general more complex compared with oscillating water column systems. This, together with additional problems associated with mooring, access for maintenance and the need of long underwater electrical cables.

\subsection{Fully Submerged Heaving Systems}

A fully submerged heaving device (Archimedes Wave Swing), consists of an oscillating upper part (the floater) and a bottom-fixed lower part (the basement) shown in Figure 2 [20]. The floater is pushed down under a wave crest and moves up under a wave trough. This motion is resisted by a linear electrical generator, with the interior air pressure acting as a spring.

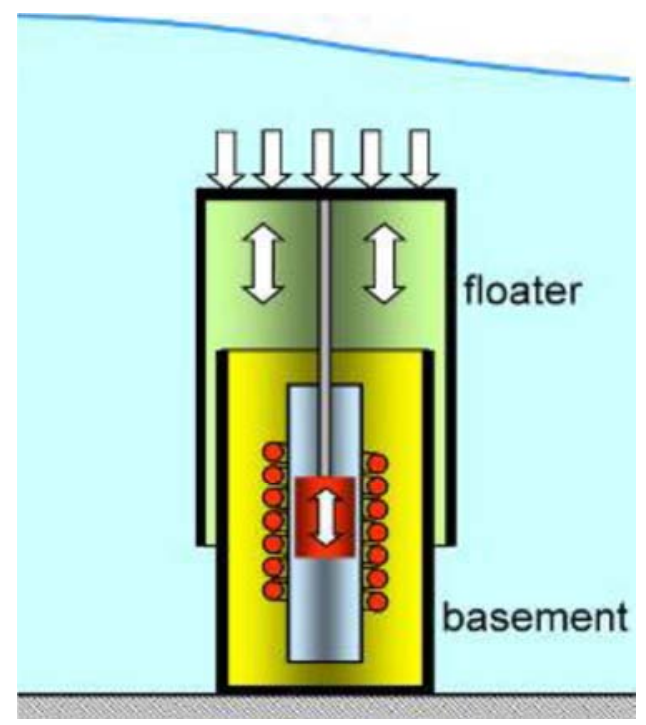

Figure 2. The Archimedes Wave Swing [20]. 


\subsection{Single-Body Heaving Buoys and Two-Body Heaving Systems}

The simplest oscillating-body device is the heaving (i.e. the energy conversion is associated with a relative translational motion) buoy reacting against a fixed frame, in most cases, such systems are conceived as point absorbers shown in Figure 3 [21]. An alternative design is a buoy connected to a bottom-fixed structure by a cable which is kept tight by a spring or similar device. The relative motion between the wave-activated float on the sea surface and the seabed structure activates a power takeoff (PTO) system.

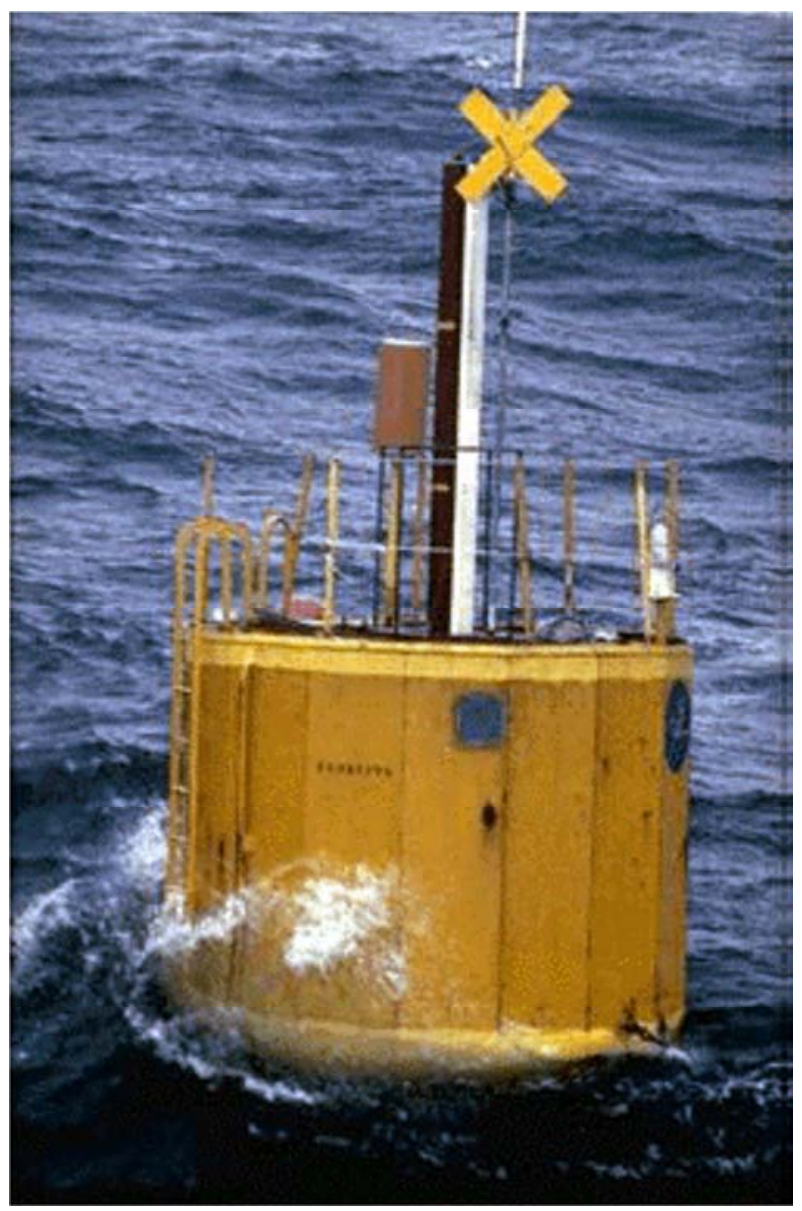

Figure 3. Heaving buoy [21].

\subsection{Pitching Devices}

The oscillating-body wave energy converters are nominally heaving systems. There are other oscillating body systems in which the energy conversion is based on relative rotation (mostly pitch) rather than translation. Basically it is a cam-like floater oscillating in pitch.

The Pelamis (Figure 4) is a snake-like slack-moored articulated structure composed of four cylindrical sections linked by hinged joints and aligned with the wave direction [19]. The wave-induced motion of these joints is resisted by hydraulic rams, which pump high-pressure oil through hydraulic motors driving four electrical generators. Gas accumulators provide some energy storage.

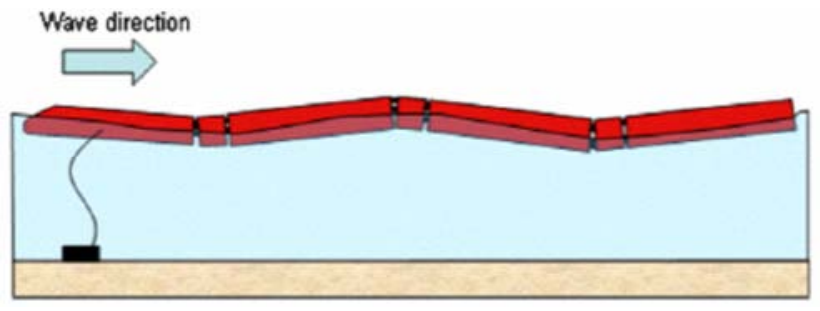

Figure 4. The four-unit of Pelamis wave farm [19].

All large-scale RE conversions are area demanding and therefore it is always in conflict with other interests. The McCabe Wave Pump consists of three rectangular steel pontoons hinged together, with the heaving motion of the central pontoon damped by a submerged horizontal plate [22] (Figure 5). Two sets of hydraulic rams and a hydraulic PTO convert the relative rotational motions of the pontoons into useful energy.

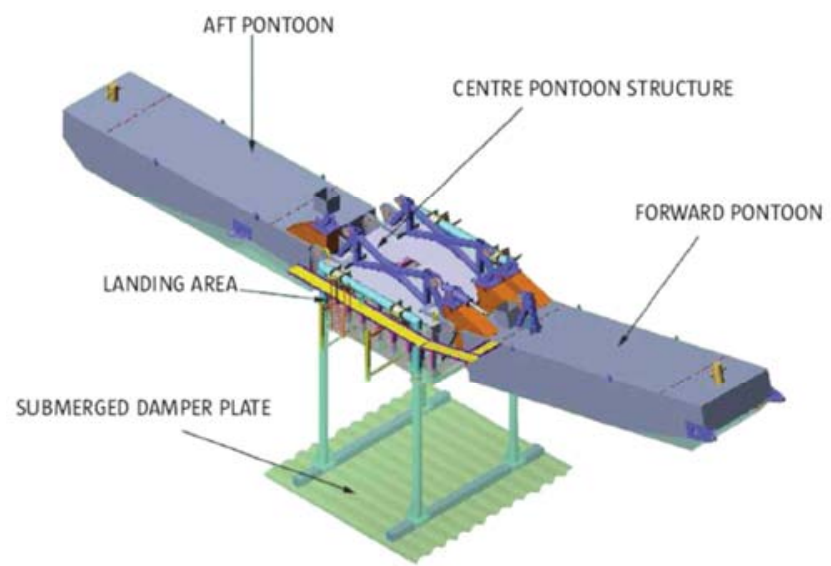

Figure 5. McCabe Wave Pump [22].

Another type of device based on the totally enclosed hull concept is the Frog. The PS Frog Mk 5 (Figure 6) consists of a large buoyant paddle with an integral ballasted handle hanging below it [23]. The waves act on the blade of the paddle and the ballast beneath provides the necessary reaction. When the WEC is pitching, power is extracted by partially resisting the sliding of a power-take-off mass, which moves in guides above sea level.

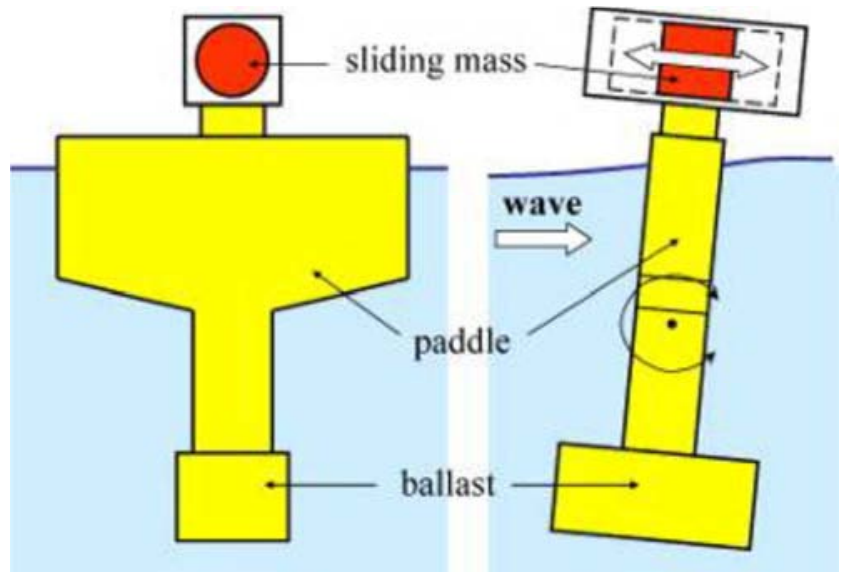

Figure 6. Schematic views of PS Frog Mk 5 [23]. 


\subsection{Overtopping Converters}

A different way of converting wave energy is to capture the water that is close to the wave crest and introduce it, by over spilling, into a reservoir where it is stored at a level higher than the average free surface level of the surrounding sea. The potential energy of the stored water is converted into useful energy through more or less conventional low-head hydraulic turbines. The hydrodynamics of overtopping devices is strongly non-linear, and, unlike the cases of oscillating body and OWC wave energy converters, cannot be addressed by linear water wave theory.

In the overtopping converters, the incident waves overtop a sloping wall (ramp) and fill a reservoir where water is stored at a level higher than the surrounding sea. This is the case of the Wave Dragon, an offshore converter, whose slackmoored floating structure consists of two wave reflectors focusing the incoming waves towards a curved ramp, a reservoir and a set of low-head hydraulic turbines (Figure 7) [24]. The water enters the reservoirs through long horizontal openings on the breakwater sloping wall, at levels corresponding to the reservoirs, and is run through a multistage hydraulic turbine for electricity production.

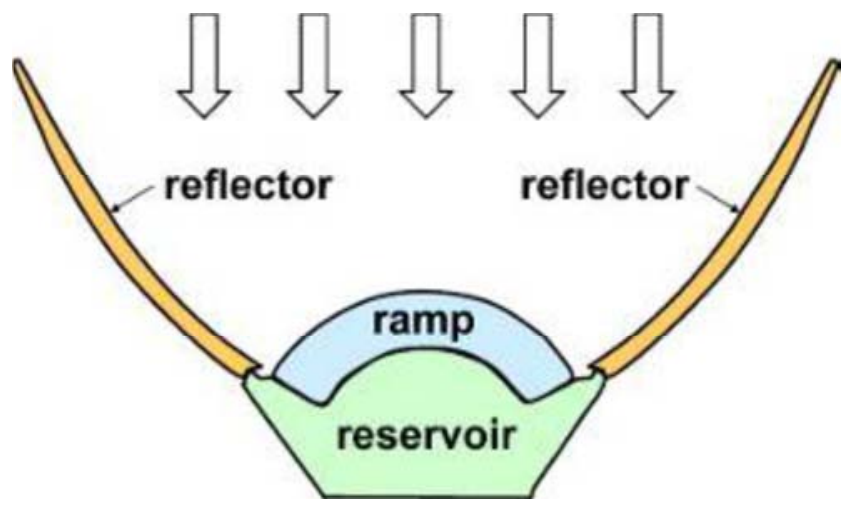

Figure 7a. schematic representation of Wave Dragon [24].

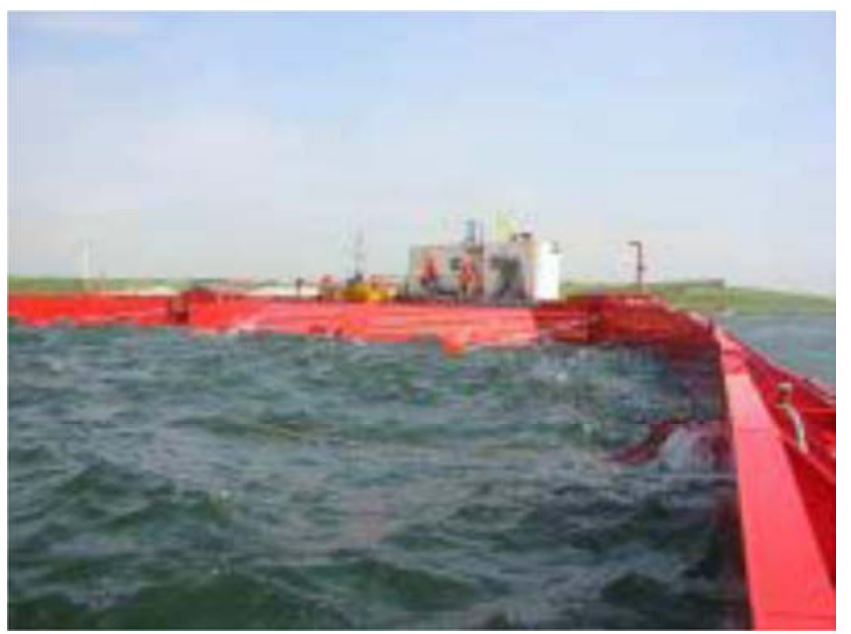

Figure 7b. Photo of Wave Dragon [24].

In most of the cases, energy generated by wave alone is not enough. For this case hybrid the wave energy with some other source of energy is recommended. One of the examples is in water supply application by researchers in Portugal and Brazil [25].

\section{Research Location}

The solar panel, wind turbine and wave energy convertor are located in a small field, on the beach located on the east side of the UMT campus premises. The fuel cell, electrolyzer, hydrogen storage tank and electrical hardware are located inside the Renewable Energy Station (RES) at the above field. The RES is located at $4^{\circ} 13.6^{\prime} \mathrm{N}$ and $103^{\circ} 26.1^{\prime} \mathrm{E}$. The site is in close proximity to the sea in the north and the east directions. The topography surrounding the RES is relatively flat and the terrain is covered by sea sand and lawn grass. Figure 8 shows the location of the chosen site.

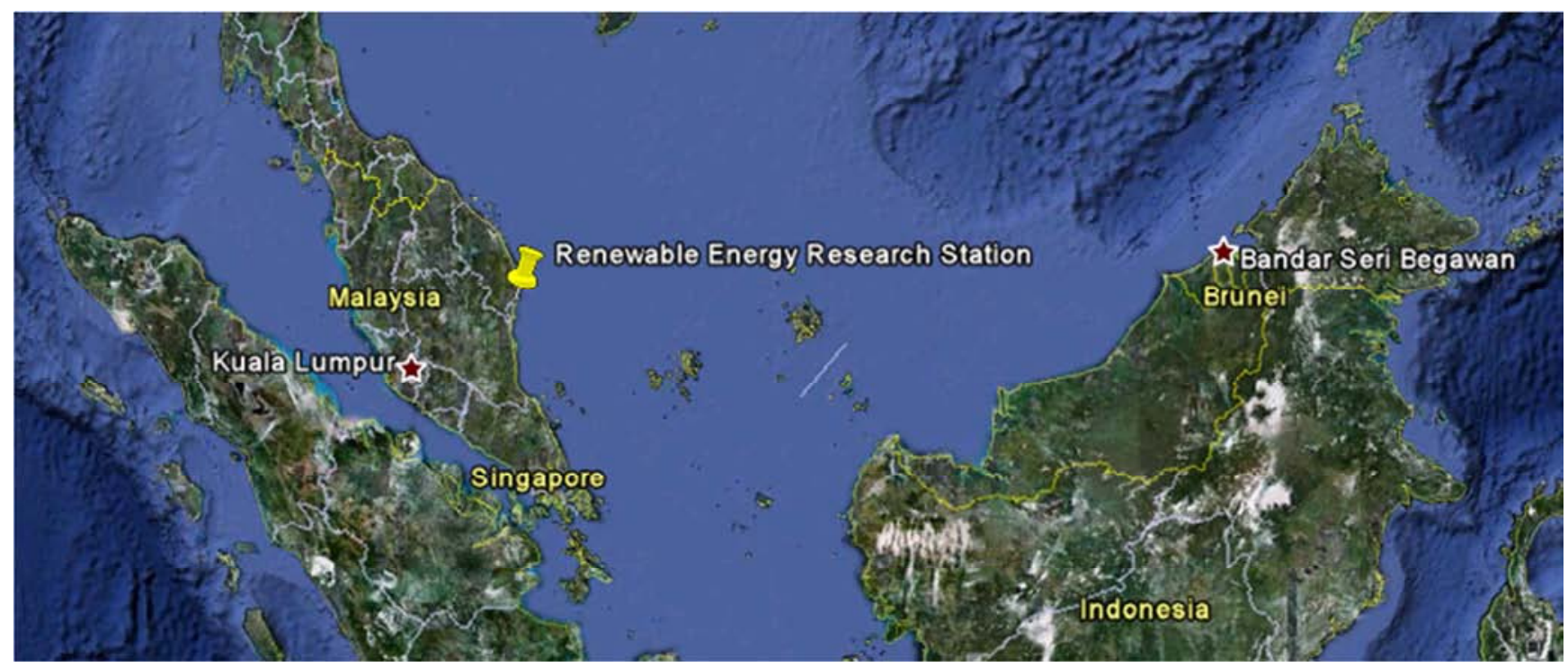

Figure 8. Location of the renewable energy station. 


\section{Wave Energy Converter for Experiments}

A wave-energy device, which is particularly suitable for the wave conditions around the Terengganu, is developed for this research. From a literature review on the existing wave-power systems, it was decided in this study to adopt the concept of the oscillating water column in a pneumatictype wave-energy conversion system shown in Figure 9 [26-27]. The design criteria for this wave-power converter were based on the actual wave statistics around the Terengganu coast.

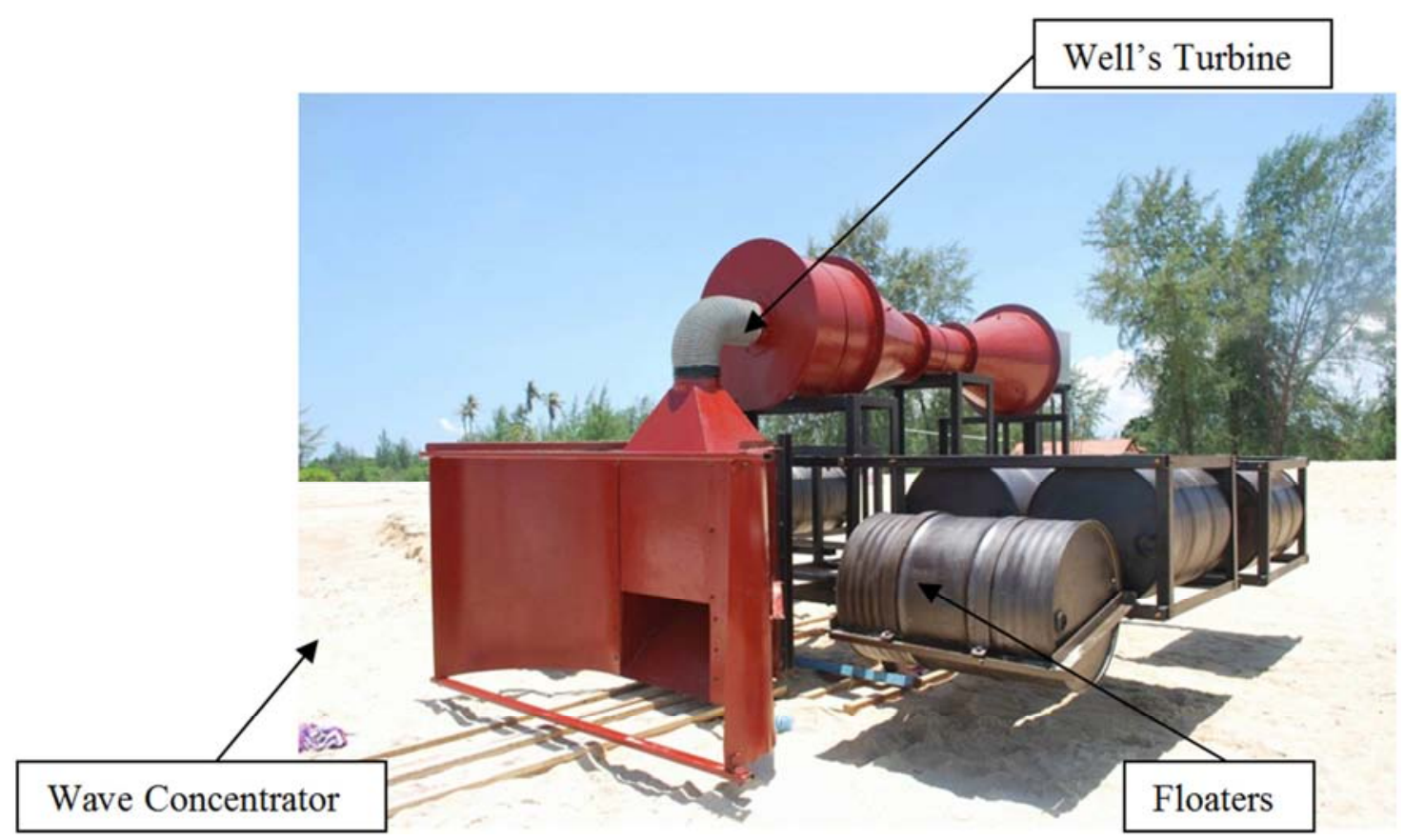

Figure 9. Custom made wave energy converter [26-27].

The oscillating water column (OWC) wave energy converter (WEC) comprises a partly submerged structure open below the water surface, inside which air is trapped above the free-surface of water. The oscillating motion of the internal free-surface produced by the incident waves causes the air to flow through the turbines that drive the electric generators. Several shoreline OWC-type WECs prototypes were built. In those OWC-WECs, the air turbine is either of vertical axis or of horizontal axis.

Floating versions of the OWC-WEC are to be installed offshore in arrays. The energy conversion chain in an OWCWEC includes the wave-to-pneumatic conversion in the OWC chamber; the pneumatic-to-shaft conversion in the turbine and the electrical energy conversion. The air turbine is the most critical element of the energy conversion chain of an OWC-WEC. It is subject to much more demanding conditions than the turbines in any other application.

A typical problem for the OWC system is the design of the air-chamber and the duct, between the water column freesurface (large cross-sectional area and low velocity) and the turbine entrance (small cross-sectional area and high velocity), which requires a sense of balance between safety and efficiency. The air passage should be designed to be as smooth and short as possible, avoiding sudden changes in the flow direction, to prevent poor distribution of the flow at the turbine inlet section, which would seriously reduce the turbine efficiency. A straight vertical connection between the air chamber and the turbine may also raise problems, due to the interaction of the inward air-jet (from the turbine duct) with the water free-surface, which may produce water-spray that in turn might be ingested by the turbine. This may affect the turbine aerodynamic performance and produce severe erosion by droplet impact on the rotor blades. Therefore, horizontal axis turbine was used in this research.

To increase the energy extraction efficiency of the wavepower device, the amplification factor of the wave amplitude inside the caisson chamber should be designed to be as large as possible. In order to investigate the flow conditions and conversion efficiencies of this wave-energy device, a real test was conducted in the wave tank at University Malaya.

In this project, one custom made OWC wave energy convertor is used. The overall dimension of the OWC system is $4300 \mathrm{~mm} \times 3900 \mathrm{~mm} \times 2100 \mathrm{~mm}$. The effective wave length of the WEC is $0.6 \mathrm{~m}$. It is equipped with Wells turbine and wave concentrator. The custom made Wells turbine diameter is $300 \mathrm{~mm}$ and mounted in a horizontal position. The WEC consists of a Windstream Power ${ }^{\circledR} 443542$ high rpm permanent magnet $\mathrm{DC}$ generator.

The WEC is rated to produce $300 \mathrm{~W}$ of electricity. The DC generator is mounted horizontally on back side of the oscillating water column. The WEC is secured with two anchor-moorings and two wires secured on the beach. In this project, the WEC is located near to the RES building (around $150 \mathrm{~m}$ ). The WEC was performed well particularly at low wave heights. 
Initially, the custom made oscillating water column, WEC, was designed as a floating system. Due to system efficiency and installation difficulties in sea water, (about $10 \mathrm{~m}$ from the beach), the WEC system was redesigned as a shore system. The WEC system was the most difficult system to install and testing. Initial WEC commissioning efforts revealed a number of problems that present barriers to the development of a hybrid renewable energy system. Further, the WEC performance was not evaluated on schedule due to the problems encountered due to factors such as water depth, safety, electrical connections and instrumental measurements. After several trail tests and adjustments, experiments with the WEC system were conducted to clarify device capabilities. Then, the operation of the system was found to be considerably good. To maintain the system performance, WEC needs frequent maintenance and observations. It is to be observed that most of the time; the system's electrical production is below the rated capacity.

\section{Data and Methodology}

The area of interest in this study is Terengganu coast of Malaysia facing South China Sea bounded by latitudes $3^{\circ} 30.0^{\prime} \mathrm{N}$ and $6^{\circ} 30.0^{\prime} \mathrm{N}$ and longitudes $102^{\circ} 30.0^{\prime} \mathrm{E}$ and $104^{\circ} 30.0^{\prime} \mathrm{E}$. The wave climate investigation was based on one and two-hourly data collected at wave measurement pointes covering the period from 1998 to 2010. The primary datasets from 2008 to 2010 collected for this research were acquired at under water fixed platform at latitude $5^{\circ} 35.0^{\prime} \mathrm{N}$ and longitude $102^{\circ} 55.5^{\prime} \mathrm{E}$ (near to one of the island). The acoustic wave and current instruments belong to UMT was deployed at $20 \mathrm{~m}$ water depth, $5 \mathrm{~km}$ from shore. These data are recorded continuously and simultaneously at $1 \mathrm{~Hz}$. These data are transmitted on a monthly basis and now constitute the largest, continuously recorded set of wave data on the study area. This constituted data provides large sample of data. Secondary datasets obtained from Malaysian Meteorology Department is available, at one hour frequency (sampling interval) covering the period from 1998 to 2009.

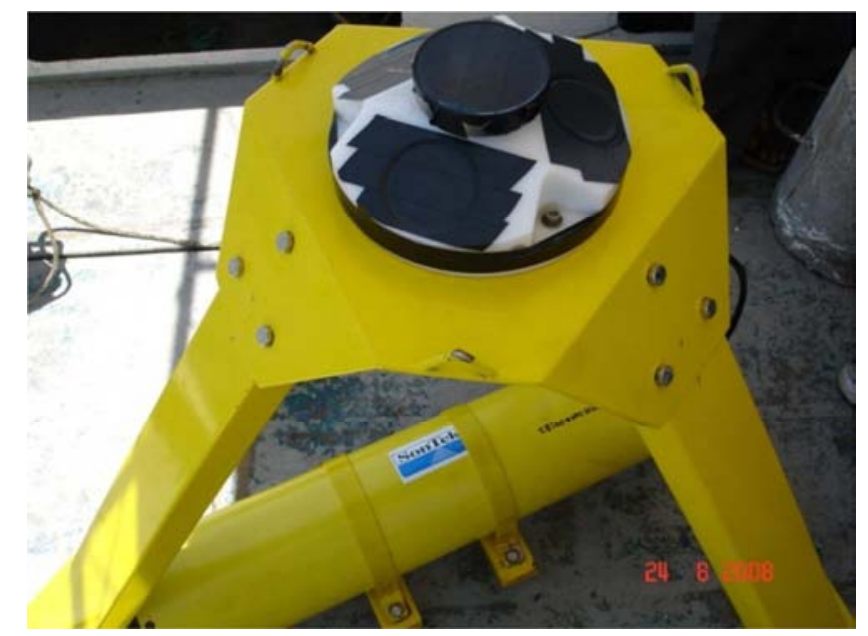

Figure 10. Nortek ${ }^{\circledR}$ AWAC equipped with an external battery fixed to deployment frame.

The acoustic wave and current (AWAC) is a combination acoustic Doppler current profiler and directional wave gauge. In this research, the Nortek ${ }^{\circledR}$ AWAC was deployed to measure the wave data, which is shown in Figure 10. The AWAC wave processing algorithm derives a full suite of data products including, significant wave height, maximum wave height, mean period, peak period, mean direction, peak direction and directional spread. Non-directional energy spectra and the full directional spectra of wave energy are also available.

The wave climate investigation was based on data collected (wave height, wave period and wave direction) at study area covering the period from 1998 to 2010. The availability of standard meteorological data and spectral wave data, and wave height and period statistics are shown in Table 1. The standard meteorological data at each location provided the significant wave height $H_{s}$, which is calculated from the energy spectrum. Similarly, the wave period is given with the average wave mean period, $T_{m}$, calculated from the energy spectrum of similar waves.

Table 1. Summary of data used in this study.

\begin{tabular}{lllllll}
\hline $\begin{array}{l}\text { Data } \\
\text { Source }\end{array}$ & $\begin{array}{l}\text { Wave data } \\
\text { period }(\mathbf{y r})\end{array}$ & $\begin{array}{l}\text { Sampling } \\
\text { interval }(\mathbf{h})\end{array}$ & $\begin{array}{l}\text { Sampling time } \\
(\mathbf{m i n})\end{array}$ & Mean $\boldsymbol{H}_{\boldsymbol{s}}(\mathbf{m})$ & $\begin{array}{l}\text { Standard deviation } \\
\text { of } \boldsymbol{H}_{\boldsymbol{s}}(\mathbf{m})\end{array}$ & $\begin{array}{l}\text { Mean } \boldsymbol{T}_{\boldsymbol{m}}(\mathbf{s}) \\
\text { of } \boldsymbol{T}_{\boldsymbol{m}}(\mathbf{s})\end{array}$ \\
\hline MMD & $1998-2009$ & 1 & 20 & 0.88 & 0.58 & 1.84 \\
UMT & $2008-2010$ & $1 \& 2$ & 20 & 0.61 & 0.45 & 3.27 \\
\hline
\end{tabular}

The integrated hourly time-series data from multiple months, excluding incomplete data were combined for validation. Data were manually validated to remove outlier events due to failure of instruments, etc. and statistically analyzed. MATLAB was used to process raw data to generate useful wave characteristics. Using MATLAB programs the wave climate characteristics were estimated and analyzed.

\section{Results and Discussions}

Wave power along the coast of Terengganu was analyzed at a time scale considering many months to examine the seasonal dependencies. The study was based on one and twohourly data collected from wave measurement stations. Seasonal trends of wave heights, wave periods, wave directions and wave power are also discussed. The wave power potential was calculated from significant wave heights and wave peak periods [28].

These preliminary investigations show that the coast of Terengganu could provide a source of low wave power. The total wave energy density was found to be $17.69 \mathrm{MWh} / \mathrm{m}$ in an average year, whereas the average wave power density 
varied between $0.15 \mathrm{~kW} / \mathrm{m}$ and $6.49 \mathrm{~kW} / \mathrm{m}$. It may be concluded that regions along the coast of Terengganu can consider northeast monsoon period for wave energy exploitation. It was found that in this area more than $60 \%$ of the annual wave energy is provided by significant wave heights between $0.2 \mathrm{~m}$ and $1.2 \mathrm{~m}$ and waves with peak periods between 2 and $8 \mathrm{~s}$ accounted for more than $70 \%$ of the total wave energy. The main directions in terms of wave energy for whole year was $\mathrm{N}$, which accounts for more than $40 \%$, followed at some distance by NE, SW and S. Further, its high wave energy potential is available during northeast monsoon season and in general the main directions in terms of wave energy were $\mathrm{N}$ and $\mathrm{NE}$, which accounts for more than $80 \%$ of the total wave energy, which may be used as a reference for this area.

\section{Conclusion}

The main disadvantage of wave power is its largely random variability in several time-scales, from wave to wave, with sea state, and from season to season. The assessment of the wave energy resource is a basic prerequisite for the strategic planning of its utilization and for the design of wave energy devices. The present situation shows a wide variety of wave energy systems, at several stages of development, competing against each other, without it being clear which types will be the final winners. In the last few years, interest in wave energy utilization has been growing rapidly in all over the world. In general, the development, from concept to commercial stage, has been found to be difficult, slow and expensive process. The high costs of constructing, deploying, maintaining and testing large prototypes under harsh environmental conditions, has hindered the development of wave energy systems. In this paper, we have discussed some wave parameters that are related to transport, generation and variability of wave energy in the sea. Many different types of wave-energy converters have been discussed. They are classified into different groups, according to which oscillation modes, according to applied method of force reaction and according to type of wave-oscillator interface. In order to develop a commercial WEC is not a straightforward task. Many inventions still have to be made, and many challenging problems need to be solved.

\section{References}

[1] Boyle, G. (2004). Renewable energy: power for a sustainable future (2nd ed.). Oxford University Press.

[2] Muzathik, A. M., Ibrahim, M. Z., Samo, K. B. and Wan Nik, W. B. (2012). Assessment and Characterization of Renewable Energy Resources: A Case Study in Terengganu, Malaysia. Journal of Sustainability Science and Management, 7 (2), 220 229.

[3] Lund, H. and Mathiesen, B. (2007). Energy system analysis of 100 percent renewable energy systems: the case of Denmark year 2030 and 2050. In HyFC Summer School Seminar. Svendborg, Denmark.
[4] Renewable energy - Energy - European Commission (2017), https://ec.europa.eu/energy/en/topics/renewable-energy (30th May 2017).

[5] Reichling, J. P. and Kulacki, F. A. (2008). Utility scale hybrid wind-solar thermal electrical generation: a case study for Minnesota. Energy, 33, 626-638.

[6] Dahai, Z., Wei, L. and Yonggary, L. (2009). Wave energy in China: current status and perspectives. Renewable energy, 34 (11), 2089-2092.

[7] Calderon, M., Calderon, A. J., Ramiro, A. and Gonzalez, J. F. (2010). Automatic management of energy flows of a standalone renewable energy supply with hydrogen support. International Journal of Hydrogen Energy, 35 (6), 2226-2235.

[8] Muzathik, AM. (20130. Potential of Global Solar Radiation in Terengganu, Malaysia, International Journal of Energy Engineering 3 (4), 130-136.

[9] Ajai, G., Saini, R. P. and Sharma, M. P. (2010). Steady-state modelling of hybrid energy system for off grid electrification of cluster of villages. Renewable Energy, 35 (2), 520-535.

[10] Ghosh, P. C., Emonts, B., Janssen, H., Mergel, J. and Stolten, D. (2003). Ten years of operational experience with a hydrogen-based renewable energy supply system. Solar Energy, 75 (6), 469-478.

[11] Isherwood, W., Smith, J. R., Aceves, S. M., Berry, G., Clark, W. and Johnson, R. (2000). Remote power systems with advanced storage technologies for Alaskan villages. Energy, 25 (10), 1005-1020.

[12] Ibrahim, M. Z, Kamaruzzaman, S., Roziah, Z. and Muzathik, A. M. (2009). The potential of small scale environmental friendly renewable hybrid photovoltaic and wind energy generated system at Terengganu state coastal area. International Energy Journal, 10 (2). 81-91.

[13] Babarit, A., Ben Ahmed, H., Clément, A. H., Debusschere, V., Duclos, G., Multon, B. and Robin G. (2006). Simulation of electricity supply of an Atlantic island by offshore wind turbines and wave energy converters associated with a medium scale local energy storage. Renewable Energy, 31 (2), 153-160.

[14] Lund, H. (2006). Large-scale integration of optimal combinations of PV, wind and wave power into the electricity supply. Renewable Energy, 31 (4), 503-515.

[15] Francesco, F., Gary, N. and Ringwood, J. V. (2010). Variability reduction through optimal combination of wind/wave resources - An Irish case study. Energy, 35 (1), 314-325.

[16] Susan, B., Peter, W., Andrew, R. and Cornelis-van, K. G. (2010). Integration of wave power in Haida Gwaii. Renewable Energy, 35 (11), 2415-2421.

[17] Langhamer O., Haikonen K., Sundberg J. Wave powerSustainable energy or environmentally costly? A review with special emphasis on linear wave energy converters. Renewable and Sustainable Energy Reviews. 2010, 14 (4), 1329-1335.

[18] Antonio F. de O. Falcao, Wave energy utilization: A review of the technologies. Renewable and Sustainable Energy Reviews. 2010, 14 (3), 899-918. 
[19] Al-Habaibeh A., Su D., McCague J., Knight A. An innovative approach for energy generation from waves. Energy Conversion and Management. 2010, 51 (8), 1664-1668.

[20] Prado M.. Archimedes wave swing (AWS). In: Ocean wave energy (Ed. Cruz J), pp. 297-304, Springer, Berlin, 2008.

[21] Ocean Power Technologies. 2006. Making Waves in Power. www.oceanpowertechnologies.com

[22] McCormick M. E., Murthagh J., McCab P. Large-scale experimental study of a hinged-barge wave energy conversion system. 3rd European Wave Energy Conference Patras, Greece, 1998, 215-222.

[23] McCabe A. P., Bradshaw A., Meadowcroft J. A. C., Aggidis G. Developments in the design of the PS Frog Mk 5 wave energy converter. Renewable Energy. 2006, 31, 141-151.

[24] Kofoed J. P., Frigaard P., Friis-Madsen E., Sørensen H. C.
Prototype testing of the wave energy converter wave dragon. Renewable Energy. 2006, 31, 181-189.

[25] Goncalves F. V., Ramos H. M., Reis L. F. R. Hybrid energy system evaluation in water supply system production: neural network approach. International Journal of Energy and Environment 2010, 1 (1), 21-30.

[26] Wan NikWB, Sulaiman OO, Rosliza R, Prawoto Y, Muzathik AM (2011). Wave energy resource assessment and review of the technologies. International Journal of Energy and Environment (IJEE), Volume 2, Issue 6, 2011, pp. 1101-1112.

[27] Wan Nik, WB. Muzathik, AM. Samo, KB. Ibrahim, MZ. (2009). A review of ocean wave power extraction; the primary interface. International Journal of Fluid Machinery and Systems 2 (2), 156-164.

[28] Milliken, J., Joseck, F. and Wang, M. (2007). The advanced energy initiative. Journal of Power Sources, 172, 121-131. 